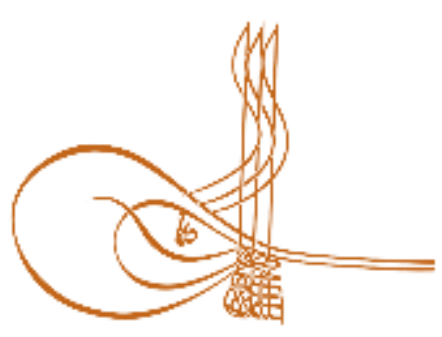

www.turkishstudies.net/social
Turkish Studies - Social Sciences

eISSN: $2667-5617$

Research Article / Araștırma Makalesi

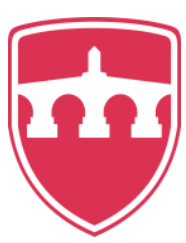

INTERNATIONAL

BALKAN

UNIVERSITY

Sponsored by IBU

\title{
Civets Ülkelerinin Karşılaştırmalı Makroekonomik Analizi
}

Comparative Macroeconomic Analysis Of Civets Countries

\author{
Birgül Cambazoğlu*
}

\begin{abstract}
The economic and political changes witnessed in various aspects across the world have led to the questioning of the country classification systems provided by international organizations, such as World Bank, Organisation for Economic Co-operation and Development and United Nations, and brought along new country groupings. In 2001, the chief economist of Goldman Sachs, Jim O'Neill researched the progress of macroeconomic indicators of several countries and concluded that some developing countries have similar economic indicators. He classified this group of countries as BRIC (Brazil, Russia, India and China). This classification produced the view that different country classification systems other than the classifications that constitute prominent international organizations, such as World Bank, Organisation for Economic Cooperation and Development and United Nations, can be acceptable in the literature. One of these groupings is CIVETS. Colombia, Indonesia, Vietnam, Egypt, Turkey and South Africa, which are included in the CIVETS grouping, were identified as so by Michael Geoghegan, who was the CEO of HSBC, in 2010. Geoghegan argued that these countries are similar in many ways, including the demographic structure. In this context, the aim of this study is to question whether CIVETS countries are similar in terms of macro indicators (especially macroeconomic indicators). CIVETS countries have a homogenous appearance considering the average age weight and population growth rate. In other words, CIVETS countries are thought to have a homogeneous outlook within the framework of their diverse dynamic structures. From this point of view, it can be said that the CIVETS group does not optimally benefit from their manpower, which is the potential source of economic growth.
\end{abstract}

Structured Abstract: In 2001, the chief economist of Goldman Sachs, Jim O'Neill researched the progress of macroeconomic indicators of several countries and concluded that some developing countries have similar economic indicators. He classified this group of countries as BRIC. This classification, which included Brazil, Russia, India, and China, produced the view that different country classification systems other than the classifications that constitute prominent international organizations such as World Bank (WB),

\footnotetext{
* Dr. Öğr. Üyesi, Aydın Adnan Menderes Üniversitesi, Söke İşletme Fakültesi, Uluslararası Ticaret ve İşletmicilik Bölümü

Asst. Prof. Dr., Aydın Adnan Menderes University, Söke Faculty of Management, International Trade and Management Department$$
\text { ORCID 0000-0001-6272-8951 }
$$

cambirgul@yahoo.com

Cite as/ Atıf: Cambazoğlu B.. (2020). Civets ülkelerinin karşılaştırmalı makroekonomik analizi, Turkish Studies Social, 15(2), 77-91. https://dx.doi.org/10.29228/TurkishStudies.40165

Received/Geliş: 14 December/Aralık 2019

Accepted/Kabul: 25 February/Şubat 2020

Checked by plagiarism software

Copyright (C) INTAC LTD, Turkey

Published/Yayın: 29 February/Şubat 2020

CC BY-NC 4.0
} 
Organisation for Economic Co-operation and Development (OECD) and United Nations (UN) can be acceptable in the literature. Also, the fact that these organizations in question have criticized the country classification systems for their several characteristics has laid the ground for this view to become more widespread. As a consequence, a rivalry of searching for similarity in terms of the progress of macroeconomic indicators has ensued among developing countries. Another country classification deriving from such search for similarity is CIVETS. In 2010, an HSBC executive, Michael Geoghegan, argued that as far as certain macro indicators are concerned, the economies of Colombia, Indonesia, Vietnam, Egypt, Turkey, and South Africa show similarity. He coined the name of CIVETS for this classification by bringing together the initials of the English names of the countries in the group (Spence, Palmer, and Oliver, 2014). Michael Geoghegan suggested that the demographic structures (a young and dynamic population and high population growth rate) and the diversified economies of CIVETS countries promised them a bright future, therefore they should be closely monitored over the next ten years. He also suggested that the strengthening of these countries over time may cause shifts in economic and political power (Reuters, 2010). Hence, the classification of CIVETS once again made developing countries the center of attention. In summary, it can be said that considering the available resources and researches regarding CIVETS, academic studies dealing with this group of countries are quite superficial. This situation is believed to be caused by the fact that some of the CIVETS countries are included in other groups (such as, N-11 and EAGLE), as well.

\section{Purpose}

In this regard, the purpose of the study is to analyze whether CIVETS countries are homogeneous in terms of fundamental macroeconomic indicators as suggested. The current study provides information on this matter with the awareness that previous research regarding CIVETS is quite superficial. We believe that such information may assist researchers to study about this topic in the future.

\section{Method}

The study follows a deductive method. The macro indicators of the CIVETS countries are comparatively presented and evaluated. Particular attention has been placed on using the most updated data set.

\section{Findings and Conclusions}

Based on the findings obtained from the study, it can be said that Indonesia and Turkey are the two significant countries in CIVETS. It can be argued that Indonesia and Turkey differ from the rest of the CIVETS countries in terms of strategic importance. The source of Indonesia's strategic importance comes from its control over the Malacca Strait, through which about 25\% of the world's energy transfer happens. The market structure and socio-economic opportunities in Turkey, that it is situated in the middle of four problematic regions (namely Balkans, Caucasia, Middle East, and the Gulf), that it links Asia and Europe together, and that it has a moderate view on economic integration make Turkey a strategically important country (Kongar, 2019). It is possible to say that the GDP and the real growth rate of Turkey are better than those of Indonesia while inflation rates, current account deficits, and unemployment rates in Indonesia are better than those of Turkey.

South Africa is a part of CIVET besides BRICS, which is a group of developing countries with emerging economies. Although the inclusion of South Africa in BRICS has been controversial with respect to its macroeconomic indicators, there are no debates regarding its inclusion in CIVETS. The importance attached to South Africa is believed to be related to the fact that it is a prominent country in an underdeveloped region. Regardless, when the change in the real growth rate of South Africa over time is considered, it is seen that this rate has been gradually decreasing in comparison with other CIVETS countries.

For Egypt, a once-promising country, it is necessary to remember that because of the political turmoil it has been experiencing since 2012, the macroeconomic outlook of the country has not improved. Banco Bilbao Vizcaya Argentaria (BBVA), which included Egypt in the EAGLE group of countries as well, described Egypt as a 'fallen angel.' Considering the data from 2017, it can be stated that the description 'fallen angel' provided by BBVA in 2012 is still true for the country. 
Based on macroeconomic indicators, it can be argued that Colombia is a medium-level member of CIVETS. Compared with other CIVETS countries, Colombia, just like Turkey, is ahead of other CIVETS countries in terms of Human Development Index indicators.

Lastly, to mention Vietnam in terms of macroeconomic indicators, when the average rates of unemployment and current account balance in the period between 2005 and 2017 are taken into consideration, it can be said that Vietnam is the leader among CIVETS countries.

As it is seen, it is difficult to reach a concrete argument by comparing CIVETS countries with each other. However, it can be said that CIVETS countries show homogeneity in terms of age average and population growth rate (demographic features). In other words, we believe that CIVETS countries have a homogeneous outlook within the context of their versatile and dynamic characteristics. This finding can be said to support the conclusion reached by Michael Geoghegan after his research. Also, it is argued that CIVETS countries cannot optimally utilize their labor force (especially women), which is their most important resource. Human Development Index indicators are invaluable tools to evaluate the effectiveness of socio-economic policies followed in CIVETS countries, and the analyses of CIVETS countries based on such indicators yields a common solution recommendation: implementation of immediate structural reforms, especially in the area of education.

Keywords: New Acronymic Country Groupings, CIVET Countries, Macroeconomic Indicators.

Öz: Dünyanın farklı yönlerde ekonomik ve politik değişimlere sahne olması başta Ekonomik Kalkınma ve İşbirliği Örgütü, Dünya Bankası ve Birleşmiş Milletler gibi uluslararası örgütlerce yapılan ülke sınıflandırma sistemlerinin sorgulanmasına ve dolayısıyla yeni ülke gruplandırmalarının ortaya çıkmasına yol açmıştır. 2001 yılında Goldman Sachs’ın baş ekonomisti Jim O’Neill, çeşitli ülkelerin makroekonomik göstergelerin seyri açısından karşılaştırmasına yönelik araştırmasında bazı gelişmekte olan ülkelerin birbirlerine yakın ekonomik göstergelere sahip olduğu sonucuna ulaşmıştır. Söz konusu ülkeleri BRIC (Brezilya, Rusya, Hindistan ve Çin) adı altında toparlamıştır. Bu ülke gruplandırması, Ekonomik Kalkınma ve İşbirliği Örgütü, Dünya Bankası ve Birleşmiş Milletler olmak üzere uluslararası örgütler dışında da farklı ülke sınıflandırma sistemlerinin literatürde kabul göreceği kanısının oluşmasına yol açmıştır. Bu gruplandırmalardan biri de CIVETS'dir. Kolombiya, Endonezya, Vietnam, Mısır, Türkiye ve Güney Afrika'yı kapsayan CIVETS gruplaması, 2010 yılında HSBC'nin CEO'su Michael Geoghegan tarafından ortaya atılmıştır. Michael Geoghegan başta demografik yapısı olmak üzere birçok açıdan bu ülkelerin benzeştiklerini savunmuştur. Bu çerçevede çalışmanın amacı, CIVETS ülkelerin makro göstergeler (özellikle de makroekonomik göstergeler) açısından benzerlik arz edip etmediklerini sorgulamaktır. CIVETS ülkelerinin ortalama yaş ağırlıkları ve nüfus artış hızları dikkate alındığında homojen görünüme sahip oldukları görülmektedir. Bir başka ifadeyle, CIVETS ülkelerinin çeşitlilik arz eden dinamik yapısı çerçevesinde homojen bir görünüme sahip oldukları düşünülmektedir. Bu noktadan hareketle, CIVETS grubunun ekonomik büyümenin potansiyel bir kaynağ olan insan gücünden optimal düzeyde yararlanamadıkları da söylenebilir.

Anahtar Kelimeler: Yeni Kısaltılmış Ülke Gruplandırmaları, CIVET Ülkeleri, Makroekonomik Göstergeler.

\section{Giriş}

2001 y1lında Goldman Sachs'ın baş ekonomisti Jim O’Neill, gelişmekte olan ülkelerin bazılarının makroekonomik göstergelerinin seyri açısından benzerlik gösterdiklerini ifade etmiştir. Benzerlik gösteren söz konusu ülkeleri, BRIC adıyla andığı grup içerisine dâhil etmiştir. Brezilya, Rusya, Hindistan ve Çin'i kapsayan BRIC grubunun en temel benzerlik gösteren yönü, incelenen zaman dilimindeki ekonomik büyüme hızlarıdır. BRIC gruplaması, ülkeler arası ve özellikle de gelişmekte olan ülkeler arası benzerlik arayışında patlama yaratmıştır. Bu furyada en çok dikkati çeken ülke gruplamaları şunlardır (Bkz. Spence, Palmer ve Oliver, 2014): MINT (Meksika, Endonezya, Nijerya ve Türkiye), N-11 (Bangladeş, Mısır, Endonezya, İran, Meksika, Nijerya, Pakistan, Filipinler, Türkiye, Güney Kore ve Vietnam), EAGLE (Brezilya, Çin, Mısır, Hindistan, Endonezya, Güney Kore, Meksika, Rusya, Tayvan ve Türkiye) ve CIVETS (Kolombiya, Endonezya, Vietnam, Mısır, Türkiye ve Güney Afrika). Söz konusu ülke gruplandırmalarından biri 
olan BRIC'e dâhil olan ülkelerin (2011 yılındaki Sansa Zirvesi'nde gruba Güney Afrika dâhil edilmiştir) ekonomik potansiyelleri göz önüne alındığında gelecekte uluslararası arenada hem politik hem de ekonomik açıdan söz sahibi olabilecek ülkeler oldukları ileri sürülmüştür. Bu iddia, BRICS grubunun diğer belirtilen gruplardan sosyo-ekonomik göstergelerin seyri açısından ileri olup olmadığı sorgusuna dayanan çalışmaların ortaya çıkmasına yol açmıştır. Bu çalışmalardan biri, Yi, Qi, ve Wu (2013)'ya aittir. Yi vd. (2013), BRICS ile CIVETS ülkelerini bilimetrik olarak karşılaştırmış ve iki grup arasında fark olmadığı sonucuna ulaşmışlardır. Anlaşıldığı üzere, BRICS grubunun alternatifi olacağı düşünülerek yaratılan her grup, BRICS ülkeleriyle kıyaslamaya tabi tutulmuştur.

2010 yılında HSBC'nin CEO'su Michael Geoghegan gelişmekte olan ülkelerin bazılarının çeşitli açılardan benzerlik gösterdiğini ifade etmiştir. Benzerlik gösterdiğini öne sürdüğü Kolombiya, Endonezya, Vietnam, Misır, Türkiye ve Güney Afrika'y1 kapsayan ve bu ülkelerin İngilizce yazımındaki baş harflerinden oluşturduğu CIVETS adıyla andığı bir grup oluşturmuştur (Spence, Palmer ve Oliver, 2014). Michael Geoghegan, CIVETS grubu ülkelerinin demografik (genç dinamik nüfusu ve nüfus artış hızı) ve çeşitlilik arz eden dinamik ekonomik yapıları kaynaklı geleceklerinin parlak olması sebebiyle önümüzdeki 10 yıllık dönem zarfında yakından izlenmeleri gerektiğini ifade etmiştir. Ayrıca, bu ülkelerin zamanla güçlenmelerinin ekonomik ve siyasal güç kaymalarına yol açabileceğini de dile getirmiştir (Reuters, 2010). CIVETS ülke gruplaması, tekrar dikkatlerin gelişmekte olan ülkelere yönelmesine yol açmıştır. Yapılan araştırmalar ve erişilen kaynaklar doğrultusunda bu gruplamaya yönelik akademik çalışmaların oldukça sı̆̆ olduğu söylenebilir. Bunun nedenin ise, CIVETS grubunda yer alan ülkelerin başka gruplandırmalara da dâhil edilmesinden kaynaklandığı düşünülmektedir.

$\mathrm{Bu}$ çerçevede çalışmanın amacı; İncelenen dönem zarfında CIVETS ülkeleri için ileri sürüldüğü üzere temel makro göstergeler açısından homojen bir yapı sergileyip sergilemediklerini sorgulamaktır. Söz konusu amaç dâhilinde CIVETS ülkelerine ait makro göstergelerin karşılaştırmalı analizi sonucunda elde edilip sunulan bilgilerin, bu konuya yönelik gelecek araştırmalara katkı sağlayacağı düşünülmektedir.

\section{CIVETS Grubunun Uluslararası Kuruluşlarca Yapılan Ülke Sınıflandırma Sistemlerindeki Konumları}

Bu bölümde Dünya Bankası (World Bank-WB), Ekonomik Kalkınma ve İşbirliği Örgütü (Organisation for Economic Co-operation and Development - OECD) ve Birleşmiş Milletler (United Nations-UN) olmak üzere uluslararası örgütlerce yapılan ülke sinıflandırma sistemlerinde CIVETS grubunun konumu sorgulanmış ve elde edilen bilgiler Tablo 1'de sunulmuştur. WB'nin ülke sınıflandırma sisteminde gelir değişkenini (kişi başına düşen GSMH) kullanarak, gelir eşik değerleri belirlenip, ülkeler sınıflandırılmaktadır. WB'nin 2019 yılında yayımladığı verilere istinaden CIVETS grubunda yer alan Endonezya, Vietnam ve Mısır'ın kişi başına GSMH değerleri 1026 -3995\$ gelir eşik değerleri arasında kaldığı için düşük-orta; Kolombiya, Türkiye ve Güney Afrika'nın değerleri ise $3996 \$$ - $12375 \$$ gelir eşik değerleri arasında kaldığ 1 için üst (yüksek)-orta gelir grubunda yer almaktadırlar (Bkz. WB, 2019a). OECD'nin ülke risk sinıflandırma (country risk category - CRC) sistemine yönelik yayımladığı 2019 yılına ait verilerine istinaden CIVETS grubunun konumuna da Tablo 1'de yer verilmiştir. CRC 3 değeri ile Endonezya, CIVETS ülkeleri içerisinde ülke riski en düşük olan ülkedir. Başka bir ifadeyle, Endonezya, CRC 3 değeriyle dünya (201 ülke dâhil) ortalamasının altında yer almaktadır. CIVETS ülkeleri içerisinde CRC 5 değerleriyle Türkiye ve Mısır ülke riski en yüksek olan iki ülkedir. Özetle; CRC değerleri açısından CIVETS grubu içerisinde yer alan Kolombiya, Vietnam, Mısır, Türkiye ve Güney Afrika dünya ortalamasının üzerinde seyretmektedirler. UN'nin 2019 yılında yayımladığı Dünya Ekonomik Durumu ve Beklentileri (World Economic Situation and Prospects -WESP) Raporu'nda ülkeler "gelişmiş", "geçiş" ve "gelişmekte olan" olmak üzere sınıflandırılmıştır. WESP'de sunulan bilgilere istinaden CIVETS ülkelerine hangi kategoride yer verildiğine bakıldığında; söz konusu 
ülkelerin hepsinin gelişmekte olan ülke gruplamasına dâhil edildikleri görülmektedir (Bkz. Tablo $1)$.

Tablo 1: WB, EOCD ve UN Ülke Sinıflandırma Sistemleri: CIVETS Grubu

\begin{tabular}{|l|c|c|c|}
\hline Ülkeler & $\begin{array}{c}\text { WB } \\
\text { (Gelir Göre Sinıflandırma) }\end{array}$ & $\begin{array}{c}\text { OECD } \\
\text { (CRC Değerleri) }\end{array}$ & $\begin{array}{c}\text { UN } \\
\text { (WESP Görünümü) }\end{array}$ \\
\hline Kolombiya & Üst-Orta Gelir Grubu & 4 & Gelişmekte Olan \\
\hline Endonezya & Düš̈u-Orta Gelir Grubu & 3 & Gelişmekte Olan \\
\hline Vietnam & Düşük-Orta Gelir Grubu & 4 & Gelişmekte Olan \\
\hline Mısır & Düşük-Orta Gelir Grubu & 5 & Gelişmekte Olan \\
\hline Türkiye & Üst-Orta Gelir Grubu & 5 & Gelişmekte Olan \\
\hline Güney Afrika & Üst-Orta Gelir Grubu & 4 & Gelişmekte Olan \\
\hline
\end{tabular}

Kaynak: WB, 2019b; OECD, 2019; UN, 2019a.

Not: Tablo, yazar tarafından oluşturulmuştur.

Özetle şu ifade edilebilir ki; CIVETS ülkeleri, UN'in ülke sınıflandırması haricindeki diğer söz konusu uluslararası kuruluşlarca yapılan ülke sınıflandırmaları içeresindeki konumları itibariyle tamamen homojen bir görünüm sergilememektedirler.

\section{CIVETS Ülkelerinin Karşılaştırmalı Analizi}

\subsection{Demografik Yapı}

İnsan gücü (özellikle de nitelikli emek), bir ülkenin ekonomik büyüme potansiyelinin en önemli kaynaklarından biri olarak görülmektedir. Bu çerçevede CIVETS ülkelerinin demografik yapılarının sorgulanmasının gerekliliği ortaya çıkmaktadır. 2018 verilerine göre nüfus yoğunluğu açısından CIVETS ülkeleri kendi içerisinde sıralandırıldığında; yaklaşık 268 milyon nüfusuyla 1811570 km² izdüşümü alana sahip Endonezya 1'inci, 98 milyon nüfusuyla $995450 \mathrm{~km}^{2}$ izdüşümü alana sahip Mısır 2'inci, 96 milyon nüfusuyla $310070 \mathrm{~km}^{2}$ izdüșümü alana sahip Vietnam 3'üncü, 82 milyon nüfusuyla $796630 \mathrm{~km}^{2}$ izdüşümü alana sahip Türkiye 4'üncü, 58 milyon nüfusuyla $1213090 \mathrm{~km}^{2}$ izdüşümü alana sahip Güney Afrika 5'inci ve 50 milyon nüfusuyla $1109500 \mathrm{~km}^{2}$ izdüşümü alana sahip Kolombiya 6'incı sıradadır (Bkz. UNCTAD, 2019a, 2019b, 2019c, 2019d, 2019e, 2019f; WB, 2018). CIVETS ülkeleri içerisinde nüfus yoğunluğu açısından birinci sırada olan Endonezya, dünya genelinde 2050'ye kadar öngörülen nüfus artışının yarısından fazlasını oluşturacağ1 düşünülen dokuz ülkeden biridir (UN, 2019b). Bu öngörünün temelinde nüfus yoğunluğu, nüfusun genç olması, ölüm oranın dünya ortalamasının altında ve doğum oranın ise dünya ortalamasında seyretmesi yatmaktadır. Endonezya, CIVETS ülkeleri içeresinde en fazla nüfus artış hızına sahip olan Mısır'ın gerisinde kalsa da nüfus yoğunluğu açısından onu geçmektedir. Vietnam dışındaki diğer CIVETS ülkelerinin ortalama nüfus artış hızları dünya ortalamasının üzerindedir.

CIVETS ülkeleri için toplam nüfusun ortalama yaş ağırlığı sorgulandığında elde edilen bilgiler şunlardır (Statista, 2017, 2019a, 2019b, 2019c, 2019d, 2019e): Kolombiya'nın 29.5 (2015 y111), Endonezya'nın 28.5 (2015 y111), Vietnam'in 30.5 (2015 y111), Misır'ın 24.3 (2015 y111), Türkiye'nin 28.2 (2010 yılı) ve Güney Afrika'nın 26.4 (2015 yıl1). ${ }^{1}$ CIVETS ülkelerinin ortalama yaş ağırlığı temel alındığında homojen bir görünüm sergiledikleri söylenebilir.

Nüfus bağımlılık oranı, bir ülkenin karşı karşıya kalabileceği sosyal ve ekonomik maliyetlere etki etmektedir. $\mathrm{Bu}$ oranın tespiti, ülkenin nüfusa yönelik gerekli yapısal düzenlemelerinin yönünü belirlemektedir. Bu doğrultuda CIVETS ülkelerini sorgulamak önem arz etmektedir. CIVETS ülkeleri içerisinde yaşlı nüfus bağımlılık oranı açısından en yüksek üç ülke Kolombiya, Türkiye ve Vietnam'dır. Bunun anlamı, bu ülkelerde gelecekte sağlık harcamalarında artış olmasının kuvvetle muhtemel olduğudur. Dolayısıyla bunun bütçeye getireceği yükün

\footnotetext{
${ }^{1}$ Tüm çalışmada küsurat hesaplamada ABD sistemi kullanılmıştır.
} 
önceden hesaplanıp, gerekli düzenlemelerin yapılması gerekmektedir. Genç nüfus bağımlık oranı açısından en yüksek ülke Mısır'dır. Ayrıca, Mısır'ın ortalama nüfus artış hızı diğer CIVETS ülkelerine kıyasla yüksektir. Bu bağlamda, Mısır'ın bütçesinden genç nüfusun eğitimine yönelik önemli bir pay ayırması gerektiği düşünülmektedir. Diğer CIVETS ülkelerine kıyasla genç nüfus bağımlık oranı dünya ortalamasının altında olan Kolombiya, Vietnam ve Türkiye'nin nüfusunun yaşlandığı söylenebilir. Bu ülkelerin gelecekte insan gücü sorunu yaşamaması için nüfus artışını teşvik etmelerinin gerekliliği ortaya çıkmaktadır.

Tablo 2: Karș1laștırmalı Nüfus Yapısı: CIVETS Ülkeleri

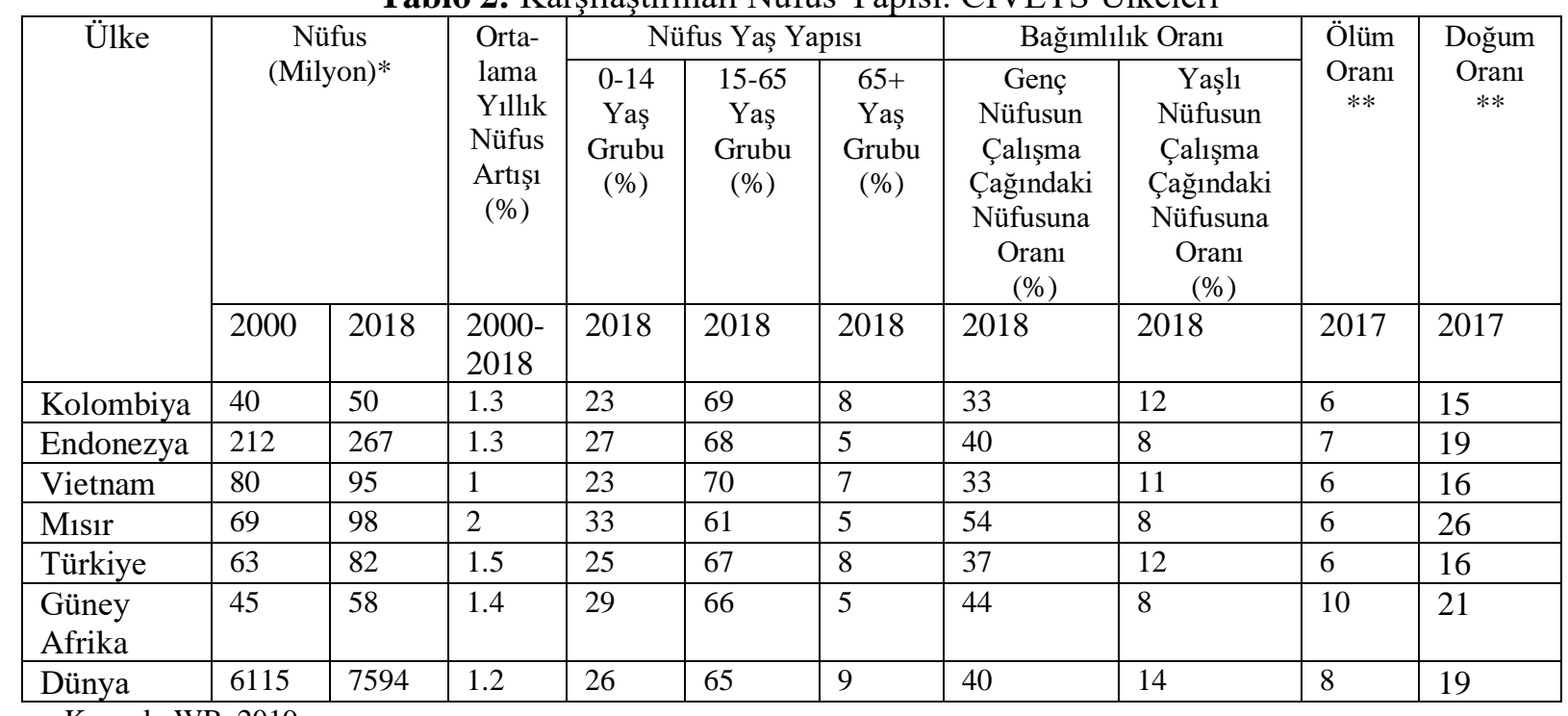

Kaynak: WB, 2019c.

Not: Tablo yazar tarafindan derlenmiştir .* sembolü yaklaşık değerleri ve ** sembolü 1000 kişi başına yaklaşı değerleri göstermektedir.

\subsection{Makroekonomik Göstergeler}

CIVETS ülkelerinin makroekonomik göstergelerinin seyri açısından benzerlik gösterip göstermediğinin sorgulanması, grubun homojen bir yapı sergileyip sergilemediğinin anlaşılmasına olanak sağlamaktadır. Bu doğrultuda elde edilen veriler Tablo 3'de sunulmaktadır. 2017 yılı için CIVETS grubu içerisinde gayri safi yurtiçi hasıla (GSYIH) değerleri açısından en iyi konumdaki ülkenin Endonezya olduğu görülmektedir. Endonezya'yı sırasıyla Türkiye, Güney Afrika, Kolombiya, Vietnam ve Mısır takip etmektedir. Ancak GSYİH değerlerinin dört yıl için ağırlık ortalaması hesaplandığında sıralama şu şekildedir: Türkiye, Endonezya, Güney Afrika, Kolombiya ve Vietnam'dır. CIVETS grubunun reel büyüme oranlarının zaman içindeki eğilimi aşağı doğrudur. 2017 yılı için CIVETS ülkelerinin reel büyüme oranları dikkate alındığında; grup içindeki en iyi konumdaki ülkenin Türkiye olduğu ve onu sırasıyla Vietnam, Endonezya, Misır, Kolombiya ve Güney Afrika'nın takip ettiği görülmektedir. Söz konusu değerlerin ağırlık ortalaması alındığında da CIVETS ülkelerinin grup içindeki sıralaması değişmemektedir. Aynı yöntemle CIVETS grubu için kişi başına düşen GSYİH değerleri hesaplandığında; en iyi konumdaki ülkenin Türkiye olduğu bulgusuna erişilmektedir. Türkiye'yi sırasıyla Güney Afrika, Kolombiya, Endonezya, Mısır ve Vietnam takip etmektedir. Endonezya'nın 4'üncü sırada yer almasının nedeninin, nüfus yoğunluğu olduğu söylenebilir.

2017 yılına göre işsizlik oranı açısından CIVETS ülkeleri içerisinde en düşük orana sahip ülke Vietnam'dır. Nüfus yapısına bakıldığında; grup içerisinde çalışma yaşı nüfus yoğunluğu en yüksek ülke olan Vietnam'ın en önemli kaynağı olan insan gücünden yararlanabildiği düşünülmektedir. Ancak bunun yeterli olup olmadığ ise tartışma konusudur. CIVETS gruplaması içerisinde Güney Afrika'nın işsizlik oranı değerlendirildiğinde en kötü konumda olan ülke olduğu 
görülmektedir. Çalışma yaşındaki nüfus yoğunluğu açısından CIVETS ülkeleri içeresinde dördüncü sırada olan Güney Afrika, 2017 yılı verilerine göre de reel büyüme oranları açısından da en kötü durumundaki ülkedir. Bu bağlamda, Güney Afrika'nın insan gücünü etkin kullanmadığı yorumu yapılabilir.

CIVETS ülkeleri için enflasyon verileri sorgulandığında şu bulgulara ulaşılmaktadır: Kolombiya'da belli dönemlerde dezenflasyon durumu görülse de fiyatlar genel düzeyinin seyrinin yukarı doğru eğilimli olduğu söylenebilir. İncelenen dönem itibariyle Endonezya'da fiyatlar genel düzeyinin aşağı doğru eğilimli olduğu görülmektedir. Vietnam, enflasyonun seyri açısından ilginç bir ülkedir. 2013 yılında yaşadığg kriz sonrasında aldığı tedbirler neticesinde Vietnam, 2015 yılında enflasyonda rekor düşüş yaşamıș ancak bu durumu elektrik, eğitim ve sağlık hizmetleri fiyatlarındaki artış kaynaklı devam ettirememiştir (Nguyen ve Pham, 2015). Enflasyonla mücadelede başarıyı yakalamış olduğu düşünülen Vietnam aynı başarıyı cari işlemlerle dengesinde de yakalamıştır. Bunun, yurtiçi fiyatlardaki düşüş temelli ithalat eğilimdeki azalış kaynaklı olduğu düşünülmektedir. Ayrıca, ithalattaki azalışın bir diğer sebebi ise, döviz kurunun yüksek seyri kaynaklı ithal malların fiyatlarındaki yükseliştir. Mısır'da fiyatlar genel düzeyinin genel seyri yukarı doğru eğilimlidir. 2015 yılında dezenflasyon süreci yaşanmış olan Türkiye'de ise, genel itibariyle fiyatlar genel düzeyinin seyri yukarı doğru eğilimlidir. Güney Afrika için de aynı yorumlama yapabilir. Genel bir değerlendirme yapılırsa; 2005- 2017 yılları arasında enflasyonla mücadelede en fazla başarıyı yakalamış iki ülkenin Endonezya (enflasyon oranı \%10.45'lerden $\% 3.81$ 'e düşüş) ve Vietnam (enflasyon oranı \%8.28'lerden \%3.52'e düşüş) olduğu söylenebilir. (Bkz. Statista, 2019c). 
Tablo 3: Makroekonomik Göstergeler: CIVET Ülkeleri

\begin{tabular}{|c|c|c|c|c|c|}
\hline \multirow[t]{2}{*}{ Ülke } & \multirow{2}{*}{$\begin{array}{l}\text { Ekonomik Göstergeler } \\
\text { ( ABD \$, milyon)*** }\end{array}$} & \multicolumn{4}{|c|}{ Yillar } \\
\hline & & 2005 & 2010 & 2015 & 2017 \\
\hline \multirow[t]{7}{*}{ Kolombiya } & GSYİH, cari* & 146566 & 287018 & 291520 & 309191 \\
\hline & Kiși başına GSYIH, cari ABD $\$ *$ & 3386 & 6251 & 6045 & 6302 \\
\hline & Reel GSYİH Büyüme (\%)* & 4.71 & 3.97 & 3.05 & 1.77 \\
\hline & Cari İșlemler Dengesi/ GSYİH (\%) * & -1.29 & -3.04 & -6.36 & -3.35 \\
\hline & Döviz Kuru (/ABD \$)* & 2320.8 & 1898.6 & 2741.9 & 2951.3 \\
\hline & İşsizlik Oranı (\%) (** $^{*}$ & 11.87 & 10.98 & 8.30 & 8.87 \\
\hline & Enflasyon Oranı (TÜFE, \%) ${ }^{* *}$ & 5.05 & 2.27 & 4.99 & 4.31 \\
\hline \multirow[t]{7}{*}{ Endonezya } & GSYİH, cari* & 304372 & 755094 & 860854 & 1015539 \\
\hline & Kişi başına GSYIH, cari ABD \$* & 1343 & 3113 & 3335 & 3847 \\
\hline & Reel GSYİH Büyüme (\%)* & 5.69 & 6.22 & 4.88 & 5.07 \\
\hline & Cari İșlemler Dengesi/ GSYİH (\%) * & 0.09 & 0.68 & -2.03 & -1.73 \\
\hline & Döviz Kuru (/ABD \$)* & 9704.7 & 9090.4 & 13389.4 & 13380.83 \\
\hline & İşsizlik Oranı (\%)** & 7.95 & 5.61 & 4.51 & 4.18 \\
\hline & Enflasyon Oranı (TÜFE, \%)** & 10.45 & 5.13 & 6.36 & 3.81 \\
\hline \multirow{7}{*}{ Vietnam } & GSYİH, cari* & 57633 & 115932 & 193241 & 223780 \\
\hline & Kişi başına GSYIH, cari ABD \$* & 684 & 1310 & 2065 & 2342 \\
\hline & Reel GSYİH Büyüme (\%)* & 7.55 & 6.42 & 6.68 & 6.81 \\
\hline & Cari İșlemler Dengesi/ GSYİH (\%) * & -0.97 & -3.69 & 0.47 & 2.74 \\
\hline & Döviz Kuru (/ABD \$)* & 15859 & 18613 & 21698 & 22371 \\
\hline & İșsizlik Oranı (\%)** & 2.22 & 1.11 & 1.86 & 1.89 \\
\hline & Enflasyon Oranı (TÜFE, \%)** & 8.28 & 8.86 & 0.88 & 3.52 \\
\hline \multirow{7}{*}{ Misir } & GSYİH, cari* & 94456 & 214630 & 317745 & 195136 \\
\hline & Kişi başına GSYIH, cari ABD \$* & 1230 & 2552 & 3388 & 2000 \\
\hline & Reel GSYİH Büyüme $(\%)^{*}$ & 4.47 & 5.15 & 4.37 & 4.18 \\
\hline & Cari İsslemler Dengesi/ GSYİH (\%) * & 2.23 & -2.10 & -5.43 & -4.74 \\
\hline & Döviz Kuru (/ABD \$)* & 5.78 & 5.62 & 7.69 & 17.78 \\
\hline & İșsizlik Oranı $(\%)^{* *}$ & 11.20 & 8.76 & 13.05 & 11.77 \\
\hline & Enflasyon Oranı (TÜFE, \%)** & 4.87 & 11.27 & 10.36 & 29.50 \\
\hline \multirow[t]{7}{*}{ Türkiye } & GSYİH, cari* & 501423 & 771877 & 859794 & 851542 \\
\hline & Kişi başına GSYIH, cari ABD \$* & 7384 & 10672 & 10985 & 10546 \\
\hline & Reel GSYİH Büyüme (\%)* & 9.01 & 8.49 & 6.09 & 7.44 \\
\hline & Cari İşlemler Dengesi/ GSYIH (\%) * & -4.18 & -5.78 & -3.73 & -5.56 \\
\hline & Döviz Kuru (/ABD \$)* & 1.34 & 1.50 & 2.72 & 3.65 \\
\hline & İşsizlik Oranı $(\%)^{* *}$ & 10.64 & 10.66 & 10.24 & 10.82 \\
\hline & Enflasyon Oranı (TÜFE, \%)** & 8.18 & 8.57 & 7.67 & 11.14 \\
\hline \multirow{7}{*}{$\begin{array}{l}\text { Güney } \\
\text { Afrika }\end{array}$} & GSYIH, cari* & 257772 & 375348 & 317536 & 348872 \\
\hline & Kişi başına GSYIH, cari ABD \$* & 5280 & 7276 & 5743 & 6151 \\
\hline & Reel GSYİH Büyüme (\%)* & 5.28 & 3.04 & 1.28 & 1.32 \\
\hline & Cari İşlemler Dengesi/ GSYİH (\%) * & -3.11 & -1.46 & -4.57 & -2.47 \\
\hline & Döviz Kuru (/ABD \$)* & 6.36 & 7.32 & 12.76 & 13.33 \\
\hline & İşsizlik Oranı $(\%)^{* *}$ & 29.25 & 24.69 & 25.16 & 27.33 \\
\hline & Enflasyon Oranı (TÜFE, \%)** & 2.06 & 4.06 & 4.51 & 5.18 \\
\hline
\end{tabular}

Kaynak: *UNCTAD, 2019a, 2019b, 2019c, 2019d, 2019e, 2019f;** WB, 2018.

Not: Tablodaki değerler aksi belirtilmedikçe ABD \$ (milyon)'dır. Tablo yazar tarafindan oluşturulmuştur.

Bir ülkenin ürün grupları sınıflandırmasına göre ihracat yapısı, o ülkenin karşılaştırmalı üstünlüğe sahip olduğu mal grupları hakkında bilgi sunmaktadır. Bu bağlamda, UNCTAD’nın 2019 yılında yayımladığ 2017 yılına ait veri seti temel alınarak CIVETS ülkelerinin ürün gruplarına göre ihracat yapıları incelenmiş̧ir. Zengin petrol ve değerli maden rezervlerine (kömür, altın, nikel vb.) sahip olan Kolombiya'nın en önemli ihracat kalemi \% 54 ile akaryakıttır. İhracatında önemli yer tutan diğer ürünleri sırasıyla sanayi ürünleri $(\% 20)$, tarım ürünleri $(\% 16)$, 
tarımsal hammadde (\% 4) ve diğer ürünler (\% 4)'dir. Kolombiya'nın en önemli ihracat pazarları sırasıyla ABD, Panama, Çin, Hollanda ve Meksika'dır (UNCTAD, 2019a). Endonezya'nın önemli ihracat ürünleri sırasıyla sanayi ürünleri (\% 42), tarım ürünleri (\%23), akaryakıt (\%22), tarımsal hammaddeler (\% 6), maden (\% 6) ve diğer ürünler (\% 1)'dir. Endonezya'nın en çok ihracat yaptığı ülkeler sırasıyla şunlardır: Çin, ABD, Japonya, Hindistan ve Singapur (UNCTAD, 2019b). Vietnam'ın ihracatında sanayi ürünleri \%79 ile önemli bir yere sahiptir. İhracatında sanayi ürünlerine kıyasla düşük de olsa yer tutan başka kalemleri ise, gıda ürünleri (\%14) ve diğer kalemleridir (\%7). Vietnam'ın en önemli ihracat pazarları sırasıyla şunlardır: ABD, Çin, Japonya, Güney Kore ve Hollanda (UNCTAD, 2019c). Misır'ın ihracatında önemli yer tutan ürün grupları sırasıyla şunlardır: sanayi ürünleri (\%46), akaryakıt (\%22), tarım ürünleri (\%17), tarımsal hammadde $(\% 4)$ ve diğer ürünler $(\% 11)$. Mısır en fazla ihracat yaptığı ülke Birleşik Arap Emirlikleri'dir. Onu sirasiyla İtalya, Türkiye, ABD ve Suudi Arabistan takip etmektedir (UNCTAD, 2019d). Türkiye ihracatında önemli yer tutan ürün grupları sırasıyla şunlardır: sanayi ürünleri (\%78), gıda ürünleri (\%11), maden (\%4) ve diğer ürünler (\%7). Türkiye'nin önemli ihracat partnerleri sırasıyla Almanya, İngiltere (Birleşik Krallık), Birleşik Arap Emirlikleri ve ABD'dir (UNCTAD, 2019e). Sanayi (\%42) ve maden ürünleri (\%24), Güney Afrika'nın ihracatında önemli yere sahip mal gruplarıdır. Güney Afrika'nın ihracat ettiği diğer ürün grupları ise ağırlığına göre sirasıyla akaryakıt (\%12), tarım ürünleri (\%11) ve diğer ürünler (\%11)'dir (UNCTAD, 2019f).

Dünya genelinde akaryakıt ihracatı açısından Kolombiya \%1.2'lik, Endonezya \%0.5'lik ve Misır \%0.2'lik paylara sahiptirler (Workman, 2019). Dünya genelinde akaryakıt ithalatında bin varil başına gündelik değer dikkate alındığında 142 ülke içerisinde Vietnam 16'ıncı, Türkiye 22'inci, Endonezya 24'üncü, Güney Afrika 26'1nc1, Misır 54'üncü ve Kolombiya 97'inci sıradadır (Index Mundi, 2019). Buradan da anlaşıldığı üzere; Vietnam ve Türkiye enerji kaynaklarına bağımlı iki ülkedir. Bu bağlamda, söz konusu ülkelerin ödemeler bilançosu açıklarının temel nedenin enerji bağımlılı̆̆ olduğu söylenebilir. Özetle; CIVETS ülkeleri içerisinde enerji kaynakları açısından en zengin ülke Kolombiya'dır.

Doğrudan yabancı sermaye (foreign direct investment (FDI)) girişlerinin özellikle gelişmekte olan ülkelerin ekonomik büyümesi üzerindeki pozitif yansımasına akademik çalışmalarda yoğunlukla değinilmektedir. Dolayısıyla, CIVETS ülkelerine yönelen doğrudan yabanc1 sermayenin sorgulanması önem arz etmektedir. 2019 yılında UNCTAD'ın yayımladığı genel ülke profili raporlarından elde edilen veriler CIVETS ülkeleri için derlenip, Tablo 4'de sunulmuştur. 2005-2017 döneminde CIVETS ülkeleri içerisinde en çok doğrudan yabancı sermaye çeken ülke Endonezya'dır. Endonezya'yı sırasıyla Türkiye, Kolombiya, Vietnam, Mısır ve Güney Afrika takip etmektedir. CIVETS grubu içerisinde yer alan Güney Afrika'nın doğrudan yabancı yatırımcı açısından en az ilgi çeken ülke olmasının nedenleri şunlardır (Masipa, 2018): Ticari bariyerlerinin yüksek olması, yabancı yatırımcı dostu olamaması, yolsuzluğun ve eşitsizliğin yüksek olması.

WB'nin 2019 yılında yayımladığı İş Yapma Kolaylığı (Ease of Doing Business - EODB) Raporu'nda 190 ekonomi içerisinde CIVETS ülkelerinin sıralaması şöyledir (WB, 2019d): Türkiye 43'üncü (74.33), Kolombiya 65'inci (69.24), Vietnam 69'uncu (68.36), Endonezya 73'üncü (67.96), Güney Afrika 82'inci (66.03) ve Misır 120'inci (58.86). Anlaşıldığı üzere; iş yapma kolaylığı açısından en iyi konumdaki ülke Türkiye iken, en kötü konumda olan ülke Mısır'dır.

CIVETS ülkeleri için FDI girişleri ile iş yapma kolaylığına dayalı veriler kıyaslandığında; diğer CIVETS ülkelerine kıyasla Endonezya'ya yönelen FDI girişlerinin yüksek olduğu görülmektedir. Bunun temel nedenin; Endonezya'nın coğrafi konumu kaynaklı suyollarına hâkimiyeti olduğu düşünülmektedir. Türkiye'nin FDI'ya yönelik yapısal düzenlemelerine karşın yeterli miktarda FDI girişi sağlayamadığı söylenebilir. Yıldırım (2018)'a göre; Türkiye'nin jeopolitik riskindeki artış kaynaklı siyasal belirsizler ve uluslararası rating kuruluşlarınca kredi notunun düşürülmesi yeterli miktarda doğrudan yabancı sermaye girişi sağlamamasına neden 
olmaktadır. İş yapma kolaylığı açısından CIVETS ülkeleri içerisinde ikinci sırada olan Kolombiya, 2012 yılında oluşturulan Pasifik İttifakı (Kolombiya, Meksika, Peru ve Şili olmak üzere bazı Güney Amerika kıtası ülkelerinden oluşan gümrük birliği)'ne üye olmuştur. Aynı yılda Latin Amerika'nın en büyük altyapı programı olan " $4 G$ " planını başlatmıştır. Ayrıca, serbest ticaret bölgelerine yönelik özel düzenlemeler de yapmıştır. İlaveten, Kolombiya, 2011 yılında ABD ile ikili serbest ticaret anlaşmasını onaylanmıştır (Export Enterprises, 2019). Tüm bu gelişmelere karşın iş yapma kolaylığı açısından CIVETS ülkeleri içerisinde 2'inci sırada yer alan Kolombiya'nın doğal zenginlikleri de düşünüldüğünde yeterli miktarda yabancı yatırım çekemediği söylenebilir. Enterprise (2019), Mısır'da yüksek enflasyonun etkisiyle yaşanan yerel talep ve dolayısıyla tüketimindeki daralmanın, doğrudan yabancı yatırımların ülkeye girişini sekteye uğrattığını ifade etmektedir. Bu durum neden Mısır'ın CIVETS ülkeleri içerisinde son sıralarda olduğunu tam olarak açıklamamaktadır. Esasen son dönemde Mısır' da yaşanan siyasal çalkantıların söz konusu durumun temel nedenlerinden biri olduğu düşünülmektedir. Son olarak, CIVETS ülkeleri işçi gelir transferi değerlerine değinmek gerekirse; CIVETS ülkeleri içerisinde en çok işçi döviz girişi olan iki ülke Vietnam ve Mısır'dır.

Tablo 4: CIVETS Ülkeleri: Finansal Akımlar

\begin{tabular}{|c|c|c|c|c|c|}
\hline \multirow[t]{2}{*}{ Ülke } & \multirow[t]{2}{*}{ Finansal Akımlar } & \multicolumn{4}{|c|}{ Yillar } \\
\hline & & 2005 & 2010 & 2015 & 2017 \\
\hline \multirow[t]{4}{*}{ Kolombiya } & FDI Girişleri (ABD \$, milyon) & 10235 & 6430 & 11736 & 14518 \\
\hline & FDI Girișleri/ GSYİH (\%) & 6.98 & 2.24 & 4.03 & 4.70 \\
\hline & FDI Çıkışları (ABD \$, milyon) & 4796 & 5483 & 4218 & 3690 \\
\hline & İşçi Dövizlerinin GSYİH Oranı (\%) & 2.28 & 1.40 & 1.61 & 1.81 \\
\hline \multirow[t]{4}{*}{ Endonezya } & FDI Girişleri (ABD \$, milyon) & 8336 & 13771 & 16641 & 23063 \\
\hline & FDI Girişleri/ GSYİH (\%) & 2.74 & 1.82 & 1.93 & 2.27 \\
\hline & FDI Çıkışları (ABD \$, milyon) & 3065 & 2664 & 5937 & 2912 \\
\hline & İşçi Dövizlerinin GSYİH Oranı (\%) & --- & 0.92 & 1.12 & 0.89 \\
\hline \multirow[t]{4}{*}{ Vietnam } & FDI Girișleri (ABD \$, milyon) & 1954 & 8000 & 11800 & 14100 \\
\hline & FDI Girișleri/ GSYİH (\%) & 3.39 & 6.90 & 6.11 & 6.30 \\
\hline & FDI Çıkışları (ABD \$, milyon) & 65 & 900 & 1100 & 540 \\
\hline & İşçi Dövizlerinin GSYİH Oranı (\%) & 5.47 & 7.12 & 6.83 & 6.16 \\
\hline \multirow[t]{4}{*}{ Misır } & FDI Girişleri (ABD \$, milyon) & 5376 & 6386 & 6925 & 7392 \\
\hline & FDI Girișleri/ GSYIH (\%) & 5.69 & 2.98 & 2.18 & 3.79 \\
\hline & FDI Çıkışları (ABD \$, milyon) & 92 & 1176 & 182 & 199 \\
\hline & İşçi Dövizlerinin GSYİH Oranı (\%) & 5.31 & 5.80 & 5.77 & 10.14 \\
\hline \multirow[t]{4}{*}{ Türkiye } & FDI Girișleri (ABD \$, milyon) & 10031 & 9086 & 17717 & 10864 \\
\hline & FDI Girișleri/ GSYİH (\%) & 2.00 & 1.18 & 2.06 & 1.28 \\
\hline & FDI Çıkışları (ABD \$, milyon) & 1064 & 1469 & 4811 & 2630 \\
\hline & İşçi Dövizlerinin GSYİH Oranı (\%) & 0.27 & 0.24 & 0.16 & 0.12 \\
\hline \multirow[t]{4}{*}{ Güney Afrika } & FDI Girişleri (ABD \$, milyon) & 6647 & 3636 & 1729 & 1325 \\
\hline & FDI Girişleri/ GSYIH (\%) & 2.58 & 0.97 & 0.54 & 0.38 \\
\hline & FDI Çıkışları (ABD \$, milyon) & 930 & -76 & 5744 & 7360 \\
\hline & İşçi Dövizlerinin GSYİH Oranı (\%) & 0.24 & 0.28 & 0.26 & 0.26 \\
\hline
\end{tabular}

Kaynak: UNCTAD, 2019a, 2019b, 2019c, 2019d, 2019e, 2019f.

Not: Tablo yazar tarafindan derlenmiş̧ir. * sembolüyle gösteriler veriler, yazar tarafindan hesaplanmıştır.

Birleşmiş Milletler Kalkınma Programı (United Nations Development Programme-UNDP) tarafindan geliştirilen İnsani Gelişme Endeksi (Human Development Index - HDI), bir ülkenin ekonomik büyüme potansiyelinin göstergelerinden biri olan insan gücüne verilen değeri göstermektedir. Ülkelerin uyguladıkları sosyo-ekonomik politikaların çıtılarını kritik edebilmeleri açısından HDI değerleri önem arz etmektedir (UNDP, 2018a). Bu çerçevede CIVETS ülkelerinin HDI değerlerinin sorgulanmasının gerekliliği ortaya çıkmaktadır. UN'in 2018 yılında yayımladığı 
189 ülkeye ait HDI değerlerine istinaden CIVETS ülkelerinin insani gelişmişlik düzeyleri sorgulanmış ve elde edilen veriler Tablo 5'de sunulmuştur.

CIVETS ülkelerinin HDI değerleri, 0.50-0.799 diliminde yer aldığ için orta düzeyde insani gelişmişliğe sahiptirler. Bununla birlikte, CIVETS ülkelerini kendi içerisinde en iyi performans gösteren ülkeden en kötüye doğru sıraladığımızda birinci sırada yer alan Türkiye'yi sırasıyla Kolombiya, Güney Afrika, Mısır, Endonezya ile Vietnam takip etmektedir. Kadınların özerklik düzeyinin düşük olması, bölgesel eşitsizlikler ve mesafeden kaynaklanan erişim engelleri, hizmet maliyetlerinin yüksek olması, doktorlara güven eksikliği ve yerel faktörler kaynaklı doğum öncesi bakıma erişimdeki eşitsizliklerin varlı̆̆g gibi nedenler Kolombiya'nın HDI değerinin Türkiye'nin gerisinde kalmasına yol açmaktadır (Bkz. Osorio, Tovar ve Rathmann, 2014). Güney Afrika'nın CIVETS ülkeleri içeresinde sonlarda yer almasının nedeni: GSMH oranı ve doğumda beklenen yaşam süresinin düşük olmasıdır (Brand South Africa, 2010). Doraid (2000)'ın belirtiği üzere, Mısır'ın HDI değerinin düşük olmasının nedeni ise; eğitim yönelik gerekli düzenlemeleri yapmasından ötürü gerekli ilerlemeyi kaydetmemiş olmasıdır. Schuler, Malesky ve Huyen (2019)'e göre; etnik köken kaynaklı yaşanan ekonomik eşitsizlikler (gelir ve servet dağılımındaki adaletsizlik) Vietnam'ın HDI değerlerinin düşük olmasının sebebidir. Vietnam'ın 1990 yılındaki HDI değeri 0.475 iken, 2018 y1lında 0.694'e yükselmiştir (UNDP, 2018c). Endonezya'nın HDI değerinin düşük olmasının temelinde uzak bölgelerde yaşayan kadın nüfusun sağlık ve eğitim imkânlarına erişim zorluğu ve etnik azınlıkların hem açık hem de gizli mahrumiyetler yaşamasıdır. Diğer bir söylemle, sağlık hizmetlerine erişim zorluğu ve gelir (ve servet) dağılımının adil olmaması, Endonezya'nın HDI değerinin düşük olmasına yol açmaktadır (UNDP, 2017). Özetle; orta düzey insani gelişmişlik seviyesindeki ülkeler grubunda yer alan CIVETS grubu içerisinde en iyi performans gösteren ülke Türkiye iken, en kötü durumdaki iki ülke ise Vietnam ile Endonezya'dir.

Tablo 5: İnsani Gelişme Endeksi: CIVETS ülkeleri

\begin{tabular}{|l|c|c|c|c|c|c|}
\hline Ülke Adı & $\begin{array}{c}\text { Dünya } \\
\text { Siralamasındaki } \\
\text { Yeri }\end{array}$ & HDI & $\begin{array}{c}\text { Doğumda } \\
\text { Beklenen } \\
\text { Yaşam Süresi } \\
\text { (Yı1) }\end{array}$ & $\begin{array}{c}\text { Beklenen } \\
\text { Eğitim } \\
\text { Süresi } \\
\text { (Y1l) }\end{array}$ & $\begin{array}{c}\text { Ortalama } \\
\text { Okul Y1lı } \\
\text { (Y1l) }\end{array}$ & $\begin{array}{c}\text { Kişi Başına } \\
\text { GSMH } \\
\text { (PPP \$) }\end{array}$ \\
\hline Kolombiya & 90 & 0.747 & 74.6 & 14.4 & 8.3 & 12,938 \\
\hline Endonezya & 116 & 0.694 & 69.4 & 12.8 & 8 & 10,846 \\
\hline Vietnam & 116 & 0.694 & 76.5 & 12.7 & 8.2 & 5,859 \\
\hline Misır & 115 & 0.696 & 71.7 & 13.1 & 7.2 & 10,355 \\
\hline Türkiye & 64 & 0.791 & 76 & 15.2 & 8 & 24,804 \\
\hline Güney Afrika & 113 & 0.699 & 63.4 & 13.3 & 10.1 & 11,923 \\
\hline
\end{tabular}

Kaynak: UNDP, 2018b.

Not: Yazar tarafindan derlenmiştir.

\section{Sonuç}

$\mathrm{Bu}$ çalışmanın amacı; son dönemde çeşitli uluslararası kuruşlarca yayınlanan verileri temel alarak, CIVETS ülkelerinin makro göstergelerinin seyri açısından benzerlik arz edip etmediklerini sorgulamaktır. 2005-2019 dönemine ait veriler dikkate alındığında makroekonomik göstergelerin seyri açısından CIVETS ülkelerini kendi içerisinde sıralandığında değişkenlik göstermektedir.

CIVETS grubu içerisinde Endonezya ve Türkiye dikkati çeken iki ülkedir. Endonezya ve Türkiye'nin stratejik önem açısından diğer CIVETS ülkelerinden ayrışsığı söylenebilir. Endonezya'nın dünya enerji nakliyatının yaklaşık \% 25'nin gerçekleştiği Malakka Boğazı üzerinde söz sahibi olması stratejik öneminin kaynağıdır. Türkiye'nin Balkanlar, Kafkaslar, Ortadoğu ve Körfez olmak üzere dört sorunlu bölgenin ortasında yer almas1, Asya ve Avrupa'yı birbirine bağlaması, ekonomik entegrasyona 1 lımlı bakışı, pazar yapısı ve sosyo-ekonomik olanaklara sahip olması stratejik açıdan önemli olmasını sağlamaktadır (Bkz. Kongar, 2019). GSYİH ve reel 
büyüme oranları dikkate alındığında Türkiye'nin Endonezya'dan daha iyi konumda olduğu görülmektedir. Enflasyon oranlarına, cari işlemler açıklarına ve işsizlik oranlarına bakıldığında ise; Endonezya'nın Türkiye'den daha iyi konumda olduğu söylenebilir. HDI değerleri açısından ise; Endonezya, Türkiye'nin oldukça gerisinde yer almaktadır.

BRICS adıyla anılan yükselen ve gelişmekte olan ülke gruplamasında yer alan Güney Afrika, CIVETS grubu içerisinde de yer almaktadır. Makroekonomik görümü kaynaklı Güney Afrika'nın BRICS grubuna dâhil edilmesi sorgulanan bir durum iken, CIVETS gruplandırması içerisinde yer almasıyla ilgili herhangi bir tartışmaya rastlanılmamıştır. Güney Afrika'ya bu kadar önem verilmesinin, bulunduğu coğrafyanın geri kalmışlı̆g içinde dikkati çeken bir ülke olmasından kaynaklandığı düşünülmektedir. Ayrıca, Güney Afrika'nın reel büyüme oranlarının zaman içindeki değişimi dikkate alındığında diğer CIVETS ülkelerine kıyasla giderek düştüğü görülmektedir.

Gelecek vaat eden ülkeler içinde görülen Misır için şunu belirtmek gerekir ki; 2012 yılından beri yaşadığı siyasal çalkantılar nedeniyle makroekonomik görümünü düzeltememiştir. EAGLE gruplandırması içerisinde yer verdiği Mısır için Banco Bilbao Vizcaya Argentaria [BBVA], bu durumu gruptan düşen ilk melek (fallen angel) tanımlamasıyla özetlemiştir. Mısır için BBVA'nın 2012 yılına ait bu tanımlamasının, 2017 yılı verileri incelendiğinde de geçerli olduğu söylenebilir.

Kolombiya değinmek gerekirse; makroekonomik göstergeler temel aldığında CIVETS ülkeleri içerisinde orta düzeyde bir yerdedir. Kolombiya'nın, Türkiye gibi, HDI değerlerinin diğer CIVETS ülkelerine kıyasla iyi olduğu görülmektedir.

Son olarak Vietnam'dan söz etmek gerekirse; makroekonomik göstergeler açısından 20052017 verilerinin ortalaması alındığında işsizlik oranı ile cari işlemler dengesinin GSYIHH oranı göz önünde bulundurulduğunda CIVETS ülkeleri içerisinde en iyi konumdaki ülke olduğu söylenebilir.

Anlaşıldığı üzere, CIVETS ülkelerini kendi içerisinde kıyasladığımızda net bir yargıda bulunmak zorlaşmaktadır. Ancak CIVETS ülkelerinin ortalama yaş ağırlığı ve nüfus artış hızı (demografik özellikler) temel alındığında homojen bir görünüm sergiledikleri söylenebilir. Bir başka ifadeyle, CIVETS ülkelerinin çeşitlilik arz eden dinamik yapısı çerçevesinde homojen bir görünüme sahip oldukları düşünülmektedir. Elde edilen bu bulgunun, Michael Geoghegan'ın araştırması sonucunda elde ettiği bulgusunu destekler nitelikte olduğu ifade edilebilir. Ayrıca, CIVETS ülkelerinin en önemli kaynağı olan insan gücünden (özellikle de kadın nüfusu) optimal düzeyde yararlanamadıkları da düşünülmektedir. CIVETS grubunun uyguladığı sosyo-ekonomik politikaların etkinliğini kritik etmeleri açısından değerli bir gösterge olan HDI değerleri sorgulandığında grup için üretilen çözüm: Özellikle eğitime yönelik yapısal düzenlemeleri ivedilikle gerçekleştirmeleri gerektiğidir. Bunun için, Akdere (2016)'nin de belirtiği üzere, CIVETS ülkelerinin insan gücünü nitelikli emeğe dönüştürebilmeleri için bilgi, beceri ve tecrübesini arttırmaya yönelik modern yaklaşımlar benimseyip, eski geleneksel yaklaşımlarını terk etmeleri gerekmektedir. Böylelikle, ülkelerindeki girişimcilik ruhunu destekleyerek, yaşam kalitesini etkileyen tüm alanların pozitif yönde etkilenmelerini sağlayacakları düşünülmektedir.

\section{Kaynakça}

Akdere, M. (2016). "Human Resource Development in the Civets Countries: Implications for Leadership and Innovation in Emerging Markets". Journal of Global Strategic Management, 10(2), 45-63. doi: 10.20460/jgsm.20161024355.

Banco Bilbao Vizcaya Argentaria [BBVA] (2012). BBVA EAGLEs Emerging and GrowthLeading $\quad$ Economies. 17.09.2019 tarihinde https://www.bbvaresearch.com/wpcontent/uploads/mult/120215_BBVAEAGLES_Annual_ 
Report_tcm348-288784.pdf https://doi.org/10.15332/tg.esp.2019.00066

adresinden

erişilmiştir.

Brand South Africa (2010). South Africa Steady on Human Development. 05.10.2019 tarihinde https://www.brandsouthafrica.com/governance/developmentnews/hdi-151110 adresinden erişilmiştir.

Doraid, M. (2000). Human Development and Poverty in the Arab States. 05.11.2019 tarihinde http://www1.aucegypt.edu/src/skillsdevelopment/pdfs/human\%20development\%20and\%20 poverty.pdf adresinden erişilmiştir.

Enterprise (2019). Why is FDI declining in Egypt and should we be worried?. 04.10.2019 tarihinde https://enterprise.press/stories/2019/04/16/why-is-fdi-declining-in-egypt-and-should-webe-worried/ adresinden erişilmiştir. https://doi.org/10.1007/978-3-030-28976-8_20

Export Entreprises (2019). Colombia: Foreign Investment. 04.10.2019 tarihinde https://en.portal.santandertrade.com/establishoverseas/colombia/investing?\&actualiser_id_ banque $=$ oui\&id_banque $=0 \&$ memoriser_choix $=$ memoriser adresinden erişilmiştir.

Index Mundi (2019). Jet Fuel Imports by Country. 02.10.2019 tarihinde https://www.indexmundi.com/energy/?product=jet-fuel\&graph=imports\&display=rank adresinden erişilmiştir.

Kongar, E. (2019). Türkiye'nin Önemi. 03.10.2019 tarihinde https://www.kongar.org/makaleler/mak_tuo.php adresinden erişilmiştir.

Masipa, T.S. (2018). "The Relationship between Foreign Direct Investment and Economic Growth in South Africa: Vector Error Correction Analysis". Acta Commercii, 18(1), 1-8, https://doi.org/10.4102/ac.v18i1.466.

Nguyen, M. ve Pham, M. (2015). UPDATE 1-Vietnam has Record Low 2015 Inflation, but Pace could Jump in 2016. 03.10.2019 tarihinde https://www.reuters.com/article/vietnameconomy/update-1-vietnam-has-record-low-2015-inflation-but-pace-could-jump-in-2016idUSL3N14D1NN20151224 adresinden erişilmiştir.

Reuters (2010, April 04). Gelecek 10 Yıla 'CIVETS' Damga Vuracak. 19.09.2019 tarihinde https://www.ntv.com.tr/ekonomi/gelecek-10-yila-civets-damgavuracak,JS70471YNU2MVY05XAnSww adresinden erişilmiştir.

O’Neill, J. (2001). Building Better Global Economic BRICs. Goldman Sachs Global Economics Paper, 66, 1-16.

Organisation for Economic Co-operation and Development [OECD] (2019). Country Risk Classifications of the Participants to the Arrangement on Officially Supported Export Credits. 30.09.2019 tarihinde http://www.oecd.org/trade/topics/exportcredits/documents/cre-crc-current-english.pdf $\quad$ adresinden $\quad$ erişilmiştir. https://doi.org/10.1787/9789264072039-en

Osorio, A. M., Tovar, L. M. ve Rathmann, K. (2014). "Individual and Local Level Factors and Antenatal Care Use In Colombia: A Multilevel Analysis". Cadernos de Saúde Pública, 30(5). http://dx.doi.org/10.1590/0102-311X00073513

Schuler, P. J., Malesky, E. J. ve Huyen, D. T. (2019). Poverty and economic inequality from Vietnamese citizens' perspective in 2018. 10.10.2019 tarihinde http://vietnamlawmagazine.vn/poverty-and-economic-inequality-from-vietnamese-citizensperspective-in-2018-16719.html adresinden erişilmiştir. 
Spence, P., Palmer, D. ve Oliver, M. (2014). Beyond the BRICs: the guide to every emerging market acronym. 17.09.2019 tarihinde https://www.telegraph.co.uk/finance/economics/11158386/Beyond-the-BRICs-the-guideto-every-emerging-market-acronym.html adresinden erişilmiştir.

Statista (2017). Turkey: Average age of the population from 1950 to 2050 (median age in years). 06.10.2019 tarihinde https://www.statista.com/statistics/255480/median-age-of-thepopulation-in-turkey/ adresinden erişilmiştir.

Statista (2019a) Colombia: Average age of the population from 1950 to 2050 (median age in years). 06.10.2019 tarihinde https://www.statista.com/statistics/368964/average-age-of-thepopulation-in-colombia/ adresinden erişilmiştir.

Statista (2019b). Indonesia: Average age of the population from 1950 to 2050 (median age in years). 06.10.2019 tarihinde https://www.statista.com/statistics/319168/average-age-of-thepopulation-in-indonesia/ adresinden erişilmiştir.

Statista (2019c). Viet Nam: Average age of the population from 1950 to 2050 (median age in years). 06.10.2019 tarihinde https://www.statista.com/statistics/444584/average-age-of-thepopulation-in-vietnam/ adresinden erişilmiştir.

Statista (2019d). Egypt: Average age of the population from 1950 to 2050 (median age in years). 06.10.2019 tarihinde https://www.statista.com/statistics/377285/average-age-of-thepopulation-in-egypt/ adresinden erişilmiştir.

Statista (2019e). South Africa: Average age of the population from 1950 to 2050 (median age in years). 06.10.2019 tarihinde https://www.statista.com/statistics/578976/average-age-of-thepopulation-in-south-africa/ adresinden erişilmiştir.

United Nations [UN] (2019a). The World Economic Situation and Prospects 2019. New York: United Nations Publishing.

United Nations [UN] (2019b). World Population Prospects 2019. New York: United Nations Publication. https://population.un.org/wpp/Publications/Files/WPP2019_Highlights.pdf adresinden erişilmiştir. https://doi.org/10.18356/13bf5476-en

United Nations Conference on Trade and Development [UNCTAD] (2019a). General Profile: Colombia. 29.09.2019 tarihinde https://unctadstat.unctad.org/CountryProfile/GeneralProfile/en-GB/170/index.html adresinden erişilmiştir.

United Nations Conference on Trade and Development [UNCTAD] (2019b). General Profile: Indonesia. 29.09.2019 tarihinde https://unctadstat.unctad.org/CountryProfile/GeneralProfile/en-GB/360/index.html adresinden erişilmiştir.

United Nations Conference on Trade and Development [UNCTAD] (2019c). General Profile: Viet Nam. 29.09.2019 tarihinde https://unctadstat.unctad.org/CountryProfile/GeneralProfile/enGB/704/index.html adresinden erişilmiş̧ir. https://doi.org/10.18356/fd7cdedd-en.

United Nations Conference on Trade and Development [UNCTAD] (2019d). General Profile: Egypt. 29.09.2019 tarihinde https://unctadstat.unctad.org/CountryProfile/GeneralProfile/en-GB/818/index.html adresinden erişilmiştir.

United Nations Conference on Trade and Development [UNCTAD] (2019e). General Profile: Turkey. 29.09.2019 tarihinde 
https://unctadstat.unctad.org/CountryProfile/GeneralProfile/en-GB/792/index.html adresinden erişilmiştir.

United Nations Conference on Trade and Development [UNCTAD] (2019f). General Profile: South Africa. 29.09.2019 tarihinde https://unctadstat.unctad.org/CountryProfile/GeneralProfile/en-GB/710/index.html adresinden erişilmiştir.

United Nations Development Programme [UNDP] (2017). Indonesia's Human Development Index Rises but Inequality Remains. 05.10.2019 tarihinde https://www.id.undp.org/content/indonesia/en/home/presscenter/pressreleases/2017/03/22/i ndonesia-s-human-development-index-rises-but-inequality-remains-.html adresinden erişilmiştir. https://doi.org/10.1093/law:epil/9780199231690/e550.

United Nations Development Programme [UNDP] (2018a). Human Development Indices and Indicators.

tarihinde http://hdr.undp.org/sites/default/files/hdr2018_technical_notes.pdf adresinden erişilmiştir.

United Nations Development Programme [UNDP] (2018b). Human Development Indices and Indicators: 2018. 05.10.2019 tarihinde http://hdr.undp.org/en/2018-update adresinden erişilmiştir. https://doi.org/10.18356/9a42b856-en.

United Nations Development Programme [UNDP] (2018c). Colombia. 04.10.2019 tarihinde http://hdr.undp.org/sites/all/themes/hdr_theme/country-notes/COL.pdf adresinden erişilmiştir.

Workman, D. (2019). Crude Oil Exports by Country. 03.10.2019 tarihinde http://www.worldstopexports.com/worlds-top-oil-exports-country/ adresinden erişilmiştir.

World Bank [WB] (2018). Countries Data. 05.09.2019 tarihinde https://data.worldbank.org adresinden erişilmiştir.

World Bank [WB] (2019a). New Country Classifications by Income Level: 2019-2020. 14.09.2019 tarihinde https://blogs.worldbank.org/opendata/new-country-classifications-income-level2019-2020 adresinden erişilmişsir.

World Bank [WB] (2019b). World Bank Country and Lending Groups. 14.09.2019 tarihinde https://datahelpdesk.worldbank.org/knowledgebase/articles/906519 adresinden erişilmiştir.

World Bank [WB] (2019c). World Development Indicators: Population Dynamics, 19.08.2019 tarihinde http://wdi.worldbank.org/table/2.1\# adresinden erişilmiştir.

World Bank [WB] (2019d). Doing Business 2019. A World Bank Group Flagship Report (16th Version). 20.08.2019 tarihinde https://www.doingbusiness.org/content/dam/doingBusiness/media/AnnualReports/English/ DB2019-report_web-version.pdf adresinden erişilmiştir.

Yi, Y., Qi, W. ve Wu, D. (2013). "Are CIVETS the next BRICs? A Comparative Analysis from Scientometrics Perspective". Scientometrics, 94(4), 615-628. http://dx.doi.org/10.1007/s11192-012-0791-9

Yıldırım, A. (2018). Para Yönünü Değiştirdi Doğrudan Yatırımlarda. 05.09.2019 tarihinde https://www.bloomberght.com/ht-yazarlar/abdurrahman-yildirim/2129965-para-yonunudegistirdi-dogrudan-yatirimlar-da adresinden erişilmişsir. 